\title{
Scrapping the Workshop of the World: Civic Infrastructuring and the Politics of Late Industrial Governance
}

\author{
ALISON KENNER \\ DREXEL UNIVERSITY
}

\begin{abstract}
To understand harm in breathing spaces requires analysis of the ways in which structural violence is built into technologies of environmental governance; a script that cannot recognize the dynamic relationships between bodies, atmospheres, and the industrial practices that condition both. In this paper, I show how community members in a small, Philadelphia neighborhood came to understand that toxic air is made permissible through late industrial political techniques. One of these techniques is a civic engagement platform, designed to more efficiently and transparently connect the public with municipal agencies, and recommended to community members as a means to address atmospheric hazards. Despite initial public optimism, the City's civic engagement platform failed to address environmental hazards. Rather than abandon the platform, however, community members appropriated the City's digital infrastructure to run an environmental reporting project. Drawing on the work of STS scholars, I describe the community's work as civic infrastructuring, a sociotechnical process that utilized public infrastructure to better understand government failure and build community capacity to engage the administration, even if on late industrial terms.
\end{abstract}

\section{Keywords}

infrastructuring; late industrialism; digital infrastructure; air pollution; environmental health; urban governance

Janet's email was brief: "The scrapyard is cutting tires right now. I called air management. If you need a violation to move forward with the case-now is the time." There was no need for salutations; everyone included on the email knew well the complaints about Overton's scrapyards--elected officials, municipal staff members, community organizers, and myself, a researcher. ${ }^{2}$ Air Management Services (AMS) was the branch of the Philadelphia Department of Public Health responsible for investigating air pollution complaints. Janet, who lived next door to

'Alison Kenner, Email: ali.kenner@gmail.com

2 Overton and Fallbrook (mentioned later) are both pseudonyms. I have also changed the names of everyone described in the article. 
the scrapyard, had sent the email quickly, on her way to visually document the smoking tires in the likely event that AMS did not arrive in time to catch the act. Admittedly, residents' videos and photos did not count for much with Philadelphia's municipal agencies. City officials needed to witness and judge for themselves whether an activity was hazardous to the community. Tire cutting in and of itself was legal. It was the byproducts that were (potentially) illegal. Smoke and toxic fumes could result in a fine, but these hazards could only be judged by a City official at the site, not through residents' media.

On a few occasions, the everyday practice of scrap processing exceeded employees' control. "Big burns," as Overton residents called them, got the City's attention by blanketing Overton in thick smoke, bringing out the Philadelphia Fire Department. Scores of social media posts as well as local news coverage documented the fires, which resulted in inspections and fines from the City. The scrapyards, however, were always able to reopen within a week of such events. The fines did little to deter hazardous practices. No amount of media coverage translated into stronger regulation, adequate compensation for impacted neighbors, or changes in industrial practice. From outside Overton, atmospheric hazards appeared to be periodic accidents. This was how they were treated by the City, anyway.

To community members, however, news-worthy scrapyard fires were an exacerbation of the everyday practices that created a toxic and unsafe environment to live in. Residents routinely documented and reported short dumping, fence line concerns, and theft. The most common reports, however, were atmospheric-noxious smells, dust clouds, and delicate trails of smoke emanating from behind the scrapyard walls. It was what Overton residents perceived in the air that concerned them. It was not the sight of tire cutting that drew Janet's attention, prompting her report to AMS. She smelled the fumes inside her home while breathing. Breathing gave community members the sense that the scrapyards were powerfully shaping their lives and health.

Breathing creates an attachment to local surroundings and neighbors, becoming a foundation for political participation. In Overton, individualized complaints like Janet's grew into larger public concern in 2014, when residents began talking about the scrapyards during community meetings. Testimonies about breathing difficulties, dust, and noxious odors were paired with residents' experiences with ineffective municipal response. The City seemed to be avoiding the scrapyard problem, or was incapable of addressing the matter. It was unclear at the time, however, where the failure in governance was situated, and if it could be remedied. Surely there were laws in place to protect against these kinds of discretions; was it an enforcement issue, a lack of resources? If the problem initially centered on the scrapyards and toxic emissions, over time it expanded to include concern with how the City was failing to protect breathing space in Overton writ large.

The City's inability to adequately investigate and respond to residents' concern with toxic harm is a problem of late industrialism. Late industrialism is a descriptive analytic that figures the ways in which environmental governance is out of step with the conditions it must regulate. While some scholars have used the term to characterize the ruins of industrial infrastructures (Mah 2017), late industrialism also points to how the very systems designed to 
govern environmental hazards and industrial practices are punctuated with legal, scientific, and discursive gaps that perpetuate toxic harm. A telltale sign you're dealing with late industrial fissures is when commonsense leads you to believe there is a law to protect against harm, but in practice, the legal and administrative structures of which the law is a part are so riddled with incongruence, bypass, and absence that it's impossible for the law to work as it should. Citizens have responded to late industrialism with an array of tactics, some of which involve adopting monitoring technologies and information systems that can address these gaps and fissures in governance (Wylie et al. 2017; Jalbert and Kinchy 2017; Kimura and Kinchy 2019; Ottinger 2010). Even in such cases, however, the politics continue to be set by the nested systems and "tight couplings" of legacy institutions, which work together to keep the system running as usual (Fortun 2014).

As a broader public became more vocal about Overton's scrapyards, the City of Philadelphia suggested that community members and local organizations use a new civic engagement platform, Philly311, to report hazards produced by the scrapyards. Designed to streamline citizen reports of environmental and public safety violations, Philly311 felt like a digital switchboard that would quickly, and publicly, register complaints with appropriate municipal departments. City officials explained that the platform would help to address the inefficiencies of municipal response, centralize communication, and keep a record of mounting violations against specific residences and businesses. A key component of the City's pitch was that Philly311 would allow residents to participate in government; that was often the point of civic technology, to increase public voice and help citizens' concerns be heard (Norris and Reddick 2013). For residents, the civic platform initially felt like a documentary mechanism (Nading 2019), where submitted reports-which included citizens photographs and accountscould stand as evidence of wrongdoing that would be actionable by the administration.

After six months of community use, however, it seemed that Philly311 was not working as it should-responses were inconsistent and slow, and air pollution complaints did not fit any of the platform's categories. This is another side of late industrialism: regulatory systems nested in information infrastructure that can't make toxics legible, nor actionable (Fortun 2014). This is when a small group of community organizers, residents, and academic researchers launched a ten-week reporting project to determine why the City continued to deflect air pollution complaints in Overton. The reporting project would use Philly311 to track how citizen complaints were categorized, parsed within municipal departments, and responded to publicly. In the shortterm, the project aimed to generate immediate improvement in the neighborhood by getting municipal agencies to address the hazards at hand. This would help residents, local organizations, and even the City itself understand how municipal departments worked: what type of complaints departments would respond to, how quickly, and whether there would be follow-up with citizens. The long-term aim of the scrapyard reporting project was to gather data that could stand as evidence that the scrapyards were hazardous to the community; the reporting data gathered using Philly311 would be presented to elected officials and municipal departments with the hope that more sustained conversations could be had about zoning, urban redevelopment, and community health. 
The scrapyard reporting project can be characterized as a form of civic infrastructuring where Overton's public appropriated an emergent municipal technology to push back on ineffective environmental governance. I borrow the term infrastructuring from scholars working in participatory design, who have shown how sociotechnical projects build capacity to address issues of public concern (Le Dantec and DiSalvo 2013; Le Dantec 2019). Infrastructuring has been taken up in many spaces to describe design processes that situate users actively in the creation of socio-technical systems (Star and Ruhleder 1996; Star 1999; Korn et al. 2019). While some scholars situate infrastructuring in terms of user engagement with information systems (Ehn 2008; Pipek and Wulf 2009), Le Dantec and DiSalvo (2013) suggest that infrastructuring can also be a process that enables public participation in democratic governance.

Infrastructuring, in this case, is characterized by several features. First, infrastructuring creates "socio-technical resources that intentionally enable adoption and appropriation beyond the initial scope of the design" (Le Dantec and DiSalvo 2013, 247), such as when a public takes up an information system or a civic app, like Philly311, and makes it work for a specific political aim. This can include capacity building among a specific community, making improvements to a system through its use or misuse (Pipek and Wulf 2009; Poirier 2017), or to provide documentation of events that are otherwise off the radar. A key distinction for Le Dantec and DiSalvo is that infrastructuring enables users to investigate an issue and discover previously unseen relationships, blind spots, and power structures. It can also help publics better understand attachments as dynamic relationships (Marres 2007). Sometimes this happens through the public's engagement in the design process itself, as in cases described by Le Dantec and DiSalvo (2013); sometimes this happens through the uptake and use of ready-made platforms (Le Dantec 2019). Infrastructuring may allow the public to reframe an issue, wrestling it back from government or other stakeholders.

In the case of Overton's scrapyard reporting project, community organizations joined with residents to design a system that would investigate public administration of environmental hazards using the City's civic engagement app, Philly311. The project enabled Overton's public to investigate the problem at hand and to build capacity within the community to engage Philadelphia's administration on issues of concern and desired outcomes. Importantly, it enabled Overton's community to center their attachment to local atmospheres, leverage sociotechnical resources that built evidence of harm, and gain a more robust understanding of why municipal enforcement failed to protect community health. The project operated in a mode of civic infrastructuring specifically because the community used the City's own civic engagement platform to investigate the workings of public administration, exposing discursive and organizational gaps in the system along the way. The technology worked as it should--in the spirit of civic engagement-but perhaps not as intended or designed by the administration, as I will describe.

Before turning to the scrapyard reporting project, in the next section I provide an overview of the late industrial conditions (Fortun 2012, 2014)--landscapes, economies, urban planning culture, and structural racism-that generated public concern and issue articulation around scrapyard hazards. I use the term issue throughout the article to connect with the work of 
Noortje Marres (2007) who describes how public concern is formulated collectively and then articulated as issues that can gain traction in different spaces of democratic governance. This work is particularly useful for the present case because part of the problem with scrapyard enforcement came down to a distinction between issues and objects: While the community gradually formulated their concern as an issue that implicated business practice, zoning law, and the ability to breathe safely in homes and backyards, the City treated the problem as an object of municipal maintenance (Hird et al. 2014). The scrapyard reporting project turned the situation around (Latour 2007) by leveraging the City's own administrative infrastructure to generate evidence of negligent governance. In the process, it also helped build public capacity to engage different branches of Philadelphia's government, using attachments to the neighborhood to articulate desired futures, even if as a cacophony of interests.

\section{Breathing the Workshop of the World}

Overton is a small neighborhood in Fallbrook, one of Philadelphia's industrial planning districts. With just over 2,700 households, Overton is a predominantly brown and Black community that has been characterized by residents as intimate and engaged. A vibrant neighborhood association works closely with a nearby community development corporation to host ad hoc events, monthly meetings, and to encourage residents' attendance at public hearings on issues impacting their neighborhood. Like many neighborhoods in Philadelphia, a lot of energy and time is spent learning about zoning and development politics. How, for example, could vacant lots become gardens or parks rather than high-end apartments? Overton is on the edge of gentrification, like many longstanding Philadelphia neighborhoods. In 2010, the median household income was $\$ 26,105$, nearly $30 \%$ lower than the city at large. This is fertile ground for developers gentrifying the City (Lubrano and Gammage 2019). But Overton's late industrial conditions also provided a protective mechanism that kept market forces at bay (Roberts 2017).

Fallbrook's landscape includes current and legacy industries leftover from the "Workshop of the World," a term used to characterize Philadelphia from the 18th through the late 20th centuries when the city was anchored by heavy concentrations of manufacturing facilities (Licht 2000). The remnants of the "Workshop" - which hosted factories, chemical plants, refineries, and ports that transported raw materials and products beyond the region--can be seen in Fallbrook's late industrial landscape. Abandoned power plants, factories, and railroads are intermixed with vacant homes and dilapidated public infrastructures that have become problematic in a number of ways. A 2013 survey found that $23 \%$ of all buildings in the neighborhood-residential, commercial, and industrial—were vacant. Public and private land is put to use in ways never intended--encampments for people experiencing homelessness, guerilla

${ }^{3}$ According to the 2010 US Census and the 2007-2011 American Community Survey, in 2010, 46\% of residents identified as Hispanic, 25\% identified as Black, 25\% identified as white, 2\% identified as Asian, and the remaining surveyed residents identified either Multiracial or other. 
gardens, informal chop shops, and opioid trade-often providing needed income, shelter, food, and space for community. No major company employer exists these days. The terrain becomes the factory, structuring the community around it.

Living in a late industrial landscape means figuring out how to navigate and leverage outdated infrastructures. For some, that has meant trading metal for cash at the scrapyards. Of the 22 acres of industrial land use in Overton, nine acres (41\% of total industrial use) are occupied by active scrapyards. Mid to late century appliances that were once the hallmark of industrialism's domestic sphere lay abandoned in vacant homes, which are systematically and repeatedly canvased for metal. Late industrial landscapes allow for a kind of alchemy, in other words, where yesteryears' products can be transmuted into resources (Pine 2016). This is the task of scrappers whose labor is most visible and their practices the shortest loop in the process of transmutation. Residents, business owners, city planners, and elected officials must also figure out how to transmute late industrial landscapes into resources. It's just a difference of proximity, and how you process the objects.

Profitable forms of scrap are non-ferrous metals: Copper, brass, aluminum, stainless steel, zinc, lead, nickel, and silver. Such metals are often used for pipes, cables, outdoor building materials such as roofs and gutters. Scrapyards accept aluminum siding, rims and radiators; brass turnings; car batteries; copper tubing, dirty roofing copper, enameled copper; lead shots, red brass, tin babbits, stainless steel, and wiring harness. When materials come into the scrapyard, they must be sorted, shredded or compacted and then stored until sold to an end user. Day to day, scrap traders can be seen walking in on foot, pushing shopping carts, or driving pickup trucks and vans. Those with vehicles are often licensed scrappers; those on foot are typically informal traders working for quick cash payments. Local scrappers operate with greater speed and efficiency than the City's Streets Department and can be called on to remove large junk items in mere hours. It matters not whether they have a license to operate.

Like many US cities, late industrial activities in Philadelphia are concentrated, segregated, into Black and brown communities. The concentration of scrapyards in Overton demonstrates this and can be understood as structural racism enacted in urban planning processes that include zoning laws. In 2015, for example, the Philadelphia City Planning Commission drafted, discussed, and finalized Fallbrook's district development objectives, in line with broader, city-wide planning mandates. Some Overton community members and local organizations wanted scrapyards out of the neighborhood. Overton's residents repeatedly asked City staff for more green space, including parks and trees, that would make the neighborhood more livable and inviting. City planners and nonprofits, too, have formally drafted planning documents that explain how Fallbrook could convert its late industrial assets into green infrastructure. The abandoned railroad viaduct, for example, has been discussed as a potential site for a park and urban trail. In its current state, however, the viaduct-which lines the row of scrapyards--draws illegal activity, including dumping, drug use, prostitution, and violent crimes. Everyone, Overton residents especially, want to see more job creation initiatives that would provide alternatives. There has been little economic investment in the community directly since the last manufacturing plant closed in the mid-1980s. 
Despite public grievance, Overton's scrapyards were grandfathered into Fallbrook's new zoning plan. The small industrial businesses would stay where they were, buttressed between the viaduct and Overton homes. At the heart of the plan, the Philadelphia port and an adjacent section of the I-95 corridor would be expanded to accommodate what business leaders hope will be growth in industrial production and goods movement. The City's support for industrial activities through the planning process reflects how the district's late industrial infrastructure has been extended, repurposed, recycled, and remade in ways that prioritize extra-local economic interests, rather than those of Overton's residents. The City's 2015 zoning decision, which kept the scrapyards in business, perpetuates what Jeremey Trombley has called "particulate racism" (2019:110). Breathing in Overton was "inseparable from histories of racism, urban planning, and industrial and military waste" (Dillion and Sze 2016:16) that remain from Philadelphia's "workshop" economy. If Overton community members learned anything from the 2015 planning process, it was that, even if the process was designed to maximize public participation through deliberation in public forums (Jasanoff 2005; Irwin 2003; Latour 2005), government as usual would continue to prioritize industrial activities over public breathing space. Bodies, however, cannot be separated from the land they inhabit, and the histories contained therein (Murphy 2017a).

\section{The Issue of Industrial Order}

To be clear, the 2015 planning process was not the first time residents brought complaints and concerns about scrapyard hazards into the public sphere. Earlier that year, Anna, a social worker who lived a block away from one of the scrapyards, sent an email to Daniel, a community organizer who would later anchor the scrapyard reporting project. In the email, Anna described the effects she thought scrapyard operations were having on her health.

For about two months now, there has been more activity. Lately I have been having trouble breathing and I believe it is because of all the debris and trash that is being disposed in the open air. One can see it just rushing out into the air. Nothing to contain the pollution. I have been hospitalized, and have made several visits to the Emergency Room and have shared my concerns there. Shouldn't there be some kind of rule or law to protect residents or the general public from this sort of situation?

It was a question more residents asked as the scrapyards' hazards turned into a central concern for the community. Resident encounters with atmospheric hazards came up repeatedly in meetings, informal conversations, and qualitative surveys administered across Fallbrook: Open burns, smoke and noxious smells that traveled inside homes, and persistent dust clouds that saturated Overton's main thoroughfare during business hours. Concern with scrap particulates paired with concern over hazardous emissions from diesel trucks that circulated the neighborhood. Vehicles of all sizes cycled in and out of the scrapyards during the day, kicking up dust inside the yards, pulling particulates into the street. 
Sensory politics (Spackman and Burlingame 2017; Naidu 2018; Fennell 2014; Calvillo 2018) combined with the embodied, community knowledge that Fallbrook had a particularly high asthma burden. Fallbrook annually reported the highest asthma hospitalization rates among children, always doubling the city-wide average. The burden of respiratory disease reported in public health statistics paired with resident testimonials, which sometimes began by first positioning themselves as living with asthma. Given the state of air pollution and respiratory disease in the community, it seemed particularly illogical for the City to keep giving small-scale polluters a pass. Community members felt that this where economic interests conflicted with breathability in Overton.

In public meetings and informal conversations, Overton residents also compared notes about the responses they received when they reported fire and smoke to the city. At one meeting, a woman with two small children described her experience with the inadequate enforcement around scrapyard business.

I called the Fire Department several times and our problem is primarily that people will go on Silver Street when they burn stuff. They are trying to burn the rubber off the wiring. And I have taken pictures several times and they will have-it looks like a bonfire where they gather together all their materials and they just set fire to them. When you stand on the second floor of my house and you look out the window, you can see all this smoke rising and then it just makes this little beeline straight for my windows. And I have called the Fire Department, the Fire Department comes out, they extinguish the flame, the guys are still there and they are like, don't do this, it's illegal in Philadelphia, blah, blah, blah. They are like, okay. They leave, they go grab more stuff and set it on fire again. And it's just an ongoing thing. I don't know what else to do anymore. Some of our neighbors have gotten together and we have taken pictures and videos. We called everyone that we could possibly think of.

Some community members reported smoke, open fires, and toxic smells several times a month. At first, residents called atmospheric hazards into the Fire Department. They quickly learned, however, that the Fire Department does little more than visit the scrapyard to inspect complaints; they do not regulate the scrapyards or hand out violations. Air Management Services (AMS), on the other hand, the agency responsible for regulating atmospheric pollution in Philadelphia, has the authority to write citations, but no enforcement agent had ever issued an air pollution citation to an Overton scrapyard. One reason for this is that open burns were typically enacted outside AMS's regular business hours - in the morning, before AMS opened, or late at night. Timing illegal activity around off hours is a classic evasion strategy used by polluters. Yet even during business hours, AMS enforcement agents only ever arrived hours after a call was made by community members; too late to catch open burns in progress. AMS did keep records of complaints, but they were anchored by residents' "anecdotes" rather than official observations, which could stand as legal evidence in a way that citizens sensory accounts could not. This is why Janet's email was short, urgent, and sent to more than a half dozen people whose first-hand account might provide more weight. 
Neither scrappers nor the businesses where they sell their metal received any penalty for open fires, which could happen on the street in broad daylight. One enforcement agent informally told me that scrapyards were a "necessary evil" in Philadelphia, a "messy service" that "no one really wanted to go after." The scrapyards served critical economic functions: They recycled materials, and nonferrous metals specifically, which were crucial for industry; they helped clear abandoned items out of the district, placing them back into production cycles; and the yards provided income for licensed scrappers who supported themselves and their families through recycling (Parry 2015). The scrapyards were necessary from a broader political economic perspective, regardless of whether they were good neighbors for the Overton community.

As residents began to talk together in public forums, the initial concerns over air quality began to expand into a broader issue; an issue that included other kinds of hazards generated by the scrapyard economy, zoning laws, and even discussion about how to establish more parks and gardens in the neighborhood. A man who himself worked for the City came to a scrapyardfocused community meeting hoping to learn better tactics for addressing dumping in the neighborhood. He was not a regular attendee at community meetings, but like many who came out that evening, he was eager to discuss the scrapyard issue publicly.

I came here today to talk about dumping - the short dumping. And also the break ins that are a result of these scrapyards. I wrote up an email about the short dumping. I got a response back by email that they had closed the file. Well I went out to see if it had been taken care of and it hadn't so I went back and put in an official request. I shouldn't have to do that. Someone came out a few days later and picked up what had been dumped on the playground. It's a hazard not only for our kids, but you don't know what is in or out of that stuff.

Shards of consumer goods covered the sidewalks, unknown industrial liquids stained the street, and piles of burned material were regular sites outside the doors of Overton's scrapyards; the street and its sidewalks felt like an extension of the scrapyard itself. Whatever boundaries might be assumed by the 12 -ft walls that surrounded the yards made little difference to the business of scrapping, where clients hauled materials to the double-wide doors, trimmed off excess material and left remains on the sidewalk. Discarded objects did not just stay put either; the neighborhood was saturated with discarded domestic material, which tumbled into nooks and were sometimes dumped in vacant lots. The City referred to such objects as trash, but for community members, the items around the scrapyards were hazards. Trash seemed to have an innocuous feel. But as the man concerned with short dumping suggests, what gets dumped must be treated as a hazard; there is no way to know what materials or toxins may be harbored in piles of junk.

US scrapyard governance operates according to the same frame as other industrial facilities: single substance regulation (Murphy 2017a). Oil spills are regulated separately from open storage of PCB waste, which are enforced separately from fires and smoke violations. Scrapyards are governed in piecemeal fashion, violation by violation, which places the burden on communities to add up the accumulated hazards. There is no system in place for looking at the 
cumulative effects of scrapyards in place. This follows from a lack of research on scrapyards, particularly in the US context. A dated Environmental Protection Agency report cautions that heavy metal soil contamination "should be suspected" around scrapyards (1990). But contamination exceeds the metals themselves, which are only the most valuable material on the reuse market. Metals can be transmuted into money, but the material that the wires and pipes are embedded in - these are discarded and left to breakdown roadside. The late industrial alchemical process of transmutation is not isolated to the scrapyard itself, nor the metals that are traded for cash. A multitude of matter, in bits and pieces, is left behind along the way-at the site of extraction, in particles tracked out of the scrapyard, as airborne dust clouds, and, of course, as these materials seep into the ground.

While the scrapyards' environmental hazards were the primary concern articulated by community members, some also saw the yards as supporting illegal economies that made Overton a violent place to live. "They just aren't good neighbors," was not only a statement about the hazardous conduct of scrapyards, which could potentially be turned around. The expression also suggested that industrial operations--even if small-scale, or especially small-scale--had no place in Overton. Dumping, deconstruction, and degradation dominated the landscape in a space where scrapping and recycling are one of the most accessible means of making a living; or simply surviving. Some Overton residents wanted to see the scrapyards closed in order to make room for businesses that were better for the community. This perspective ran up against a more dominant view in Fallbrook, however: that there was a need for jobs, any jobs. In Fallbrook, the toxic matter of late industrialism - air pollution from interstate corridors, goods movement, and manufacturing facilities; brownfield sites, abandoned warehouses and vacant lots suspected of soil contamination-were sometimes backgrounded to more immediate economic problems, concerns with the opioid epidemic, and homelessness. Environmental hazards, community health, and the local economy were entangled issues in the minds and political priorities of community members.

Industrial order, however, privileged boundaries, property, objects, and business in ways that discounted the lived realities and concerns of Overton's community. Municipal departments who responded to complaints of environmental hazards considered smoke, odor, and waste as "things in themselves rather than connected and enmeshed" (Fortun 2014: 313). One resident who called to report an odor and smoke was told by the enforcement agent: "Look, you live next to a scrapyard, what do you expect? There is nothing we can do." The suggestion that there was nothing municipal staff could do indicated that they did not have the frameworks and thus resources to address the scrapyard issue. It wasn't only Philadelphia's administration missing the mark. Pennsylvania House Representative John J. Taylor introduced a bill to create a statewide scrap metal transaction database around the same time Overton community members were gathering in force to discuss the problem. The bill was designed to cut down on theft in Fallbrook's junk markets. Under this law, the "Scrap Metal Theft Prevention Act," all scrap processors would be required to register with the state and routinely report sales (Foster 2015). While some thought the law might bring more enforcement to the scrapyard economy, others saw it as inadequate to address the issue at hand. Theft was not part of the issue articulated by 
the Overton community; it was externally imposed and the bill clearly leveraged negative stereotypes of scrap exchange (Zimring 2009).

All of this is to say, the scrapyards indexed a much larger issue with community health and vitality in Overton. This included the desire for clean air, parks and gardens, streets free of scrap waste, and also jobs. From residents' perspectives, the scrapyards were an obvious harm to the neighborhood; anyone could smell the problem, feel it in their airways and on skin, and see the hazards across the landscape. And scrapyards were a problem that could be mobilized around; or so they thought. The strategy of calling the City to report air pollution and other hazards clearly was not working. There seemed to be a gap in the system, where Philadelphia's administration lacked the expertise, skill, and resources to address the issue identified by community members (Marres 2007). Rep. Taylor's bill was also inadequate to address environmental hazards; it worked within a framework of economic exchange only, leveraging legal infrastructure to sanction scrap traders and transactions. The way both municipal departments and elected officials addressed the problem was fragmented in bureaucratic arenas that operated on the logic of industrial order. This mismatch between public concern, which focused on the scrapyards as a source of harm, and the way government could address the problem (Marres 2007; Latour 2007) set the stage for the scrapyard reporting project.

\section{Maintaining Objects, Documenting Issues}

Philly311 felt like the perfect solution to Overton's scrapyard problem, at least in terms of eliminating hazards through government enforcement. Rather than calling municipal departments, waiting to be connected to the right person, and later wondering what happened to a complaint, Philly311 would programmatically dictate the process of reporting hazards, and it would do so much more efficiently. This was the pitch community members received when the newly launched phone app and website were presented at a public meeting in early 2015. The platform's uptake was immediate. Community members who had formerly reported violations by calling the Fire Department and AMS began using Philly311's digital platform. Philly311 staff emphasized that the platform was not just more efficient, but transparent, too. Anyone could open Philly311, find a report, and see what its status was-received, under investigation, or closed, for example. As civic engagement infrastructure, Philly311 gave community members a better view into the workings of public administration than they had when making phone calls and talking to elected officials.

Historically, 3-1-1 services were put in place as an addendum to 9-1-1, an easy to remember number for residents to call when faced with a non-emergency. 311 operators were responsible for connecting citizens and businesses to municipal departments and their information. In Philadelphia, 3-1-1 has been extended from a call-in number to a dynamic digital platform where residents can submit "civic" reports using the phone app. This is an exemplar of what some scholars called "e-governance," marked by a slow transition whereby municipal organizations crafted internet-based systems of administration, hoping to improve the effectiveness and efficiency of government information and service delivery. Internet-based 
governance was projected to "fundamentally transform relations between governments and the governed" (Norris and Reddick 2013: 165). The project of digitizing governance has been described as a paradigm shift to citizen-centric government (Ho 2002), which would increase citizen access and participation, improve communication and relationships between citizens and government, including transparency and trust (Bolivar, Perez, and Hernandez 2007; Lee, Tan, and Trimi 2005; Thomas and Streib 2003), and would be a way to "reverse the loss of social capital" in bureaucracy through renewed consultation and collaboration (Norris and Reddick 2013: 165). But emergent digital governance platforms also reflect a side of late industrialism where exhausted legal-epistemological paradigms are cast anew with digital systems (Little 2018; Fortun 2012).

When citizens submit a report through Philly311, they must move through public administration categories, which define problems according to the organization of municipal agencies: Abandoned Automobile; Dangerous Building; Fallen Tree; Graffiti Removal; Illegal Dumping; Maintenance Commercial; Maintenance Residential; Park Conditions; Pothole Repair; Recycling Collection; Rubbish Collection; Streetlight Outage; Vacant Commercial; Vacant House; Vacant Lot Clean-up. After the issue type and location are entered, the user has the option of manually entering a description of the issue, which is the only field that allows users to annotate, qualitatively, the problem. There are additional required information fields for each category of report, provided as dropdown menus. In the case of "Illegal Dumping," one of the most common issues reported around the scrapyards and Fallbrook more broadly, users are also required to indicate whether the issue includes hazardous household waste; whether the trash is located on the sidewalk, in the street, or on a vacant lot; whether the issue is co-located with an active construction area; the type of object (appliances, construction, mattresses and furniture, electronics, etc.); and whether the objects are contained in some way (in bags, loose, or in containers). Accompanying pictures helped. Once submitted the "progress" status appears at the bottom of the report: Submitted, Received, In Progress, and Completed. At the bottom of each violation is a comment feed as well.

While there is an option to create a personal account, it's just as easy to submit a report anonymously so that neither City staff nor other Philly311 users can identify who submitted the report. This is an important feature that allows residents, and also community organizers, to submit reports without fear of repercussion. Anonymity does not prevent users from getting needed updates about the issue. Philly 311 is designed for transparency; anyone can track the status of a report using its service request number. Users can also browse reported issues using the platform's map view, noting what's happening in their neighborhood, or other neighborhoods. If citizens use the website version of Philly 311, which was built using Salesforce, they are met with a social media feel that one resident suggested looked a lot like the original version of Facebook.

After community members-residents and staff at local organizations--had used Philly311 for a few months it was clear the technocratic solution wasn't working. Tire cutting, dust clouds, and noxious odors continued unabated. There was no category for air pollution reports in Philly311 so residents submitted these in the platform's "Other" category. While some 
categories seemed to be well monitored, the "Other" category simply ate residual complaints (Star and Bowker 2007). But Philly311 didn't only fail at air pollution complaints. Municipal department response to reports of fenceline hazards and abandoned materials were inconsistent and slow, too. Understandably residents were frustrated and feeling stuck. Using the City's new civic engagement platform did not produce a different outcome. If it had been uncertain before, using Philly311's platform made it clear that the City was ignoring the scrapyard issue. Or, the administration was completely unequipped to address it. The only thing the platform seemed to do well was provide evidence of government neglect. This documentary valence, however, provided the basis for civic infrastructuring using the platform.

Staff members at a local organization in Fallbrook joined with Overton's neighborhood association to initiate the scrapyard reporting project in summer 2015. The project was designed to document reports of scrapyard hazards made through Philly311 and to systematically investigate what happened to the hazards. The reporting project tracked Philly311 data for a period of ten weeks, noting what kinds of hazards were reported under which administrative categories, how quickly citizen reports moved through Philly311's platform, and whether the reports were ever truly resolved--hazard investigated, removed, and fine issued. Three community organizers managed a spreadsheet that collected all reports made during the project period. Community members could email or call organizers with reports made using the service request number, but the organizers also monitored the public facing app daily for new reports and also to track the status of existing reports. They also physically visited the locations of reported hazards to verify information in Philly311. Documentation of environmental hazards and their governance has long been a foundation of collective political action (Nading 2019; Murphy 2017b). What made the reporting project a practice of infrastructuring stemmed from the public's use of the City's digital civics initiative (Le Dantec 2019), Philly311, to understand where the system was broken; why the platform wasn't working as promised, but also (eventually) to suggest how the platform could be improved. Follow-up with municipal agencies (via phone and email) was critical to the process of infrastructuring to understand the problem. For example, community members and organizers made use of Philly311 service request numbers to get clarity on information provided through the platform.

The scrapyard reporting project could best be understood as a form infrastructuring whereby the community used Philly311 to investigate where the systemic breakdown in regulation was happening. The project did not simply leverage the platform. It was also anchored by the community's proximity to and knowledge of the scrapyards, their political commitment to do something to address the hazards as a neighborhood, as well as social capital developed through public meetings. While the aims of the scrapyard reporting project may have started with a desire to document hazards and test the workings of Philly311, through the process of infrastructuring, the reporting team discovered problems with the structures of City government that wouldn't have been observable without use of the civic platform. This would help build capacity to further engage the City on issues of environmental justice in Overton. 


\section{Infrastructuring as Political Form}

Sixty-four violations were reported using Philly311 during the 10-week reporting period. The most common violations reported were illegal dumping and "improper storage," a category used to report fence line violations, such as towers of refrigerators that extended more than six feet above the scrapyards' walls. Most reports were acknowledged within a week of submission and approximately half the issues were marked as "resolved" within a week of the department's acknowledgement. All reports were handled by one of two City municipal departments: Licenses and Inspection (L\&I) - a code enforcement agency responsible for business creation, property management, and construction activities across the city-and the Streets department. At the end of the reporting period, the project organizers presented key findings at one of Overton's monthly community meetings. Their report included data from Philly311, which was tracked in a shared spreadsheet, as well as follow-up consultations with staff at various municipal departments. These consultations were conducted by both residents and community organizers who participated in the reporting project.

One of the most important outcomes of the reporting project was increased understanding of the role and organization of municipal departments. For example, community members distinguished the two departments that responded to Philly311 reports as governing public (Streets) and private (L\&I) matters. The Streets Department responded to all illegal dumping reports (48) and L\&I responded to all fenceline violations (16). Nineteen reports were never resolved, however. Seventeen of the unresolved reports were located at one scrapyard in particular. The scrapyard was tucked away on an abandoned street, a block south of Overton's main thoroughfare. There were no homes or businesses on this block, so the initial assumption by the community was that the City just let this business slide, since it wasn't adjacent to other occupants. But it wasn't just an abandoned street; the street did not even appear on official City maps. It was unclear, at the time of the reporting project, whether the street's absence on City maps resulted in municipal neglect. The City's departments knew the business was there, but the address citizens entered into Philly311 did not correspond to a known address in the City's property database. This may have produced an error in the system, but neither municipal department could say for sure. If an error was produced by unregistered addresses, neither the City nor the reporting citizen was made aware of the problem. There was no mechanism to signal when data was illegible, in other words.

Illegible addresses were not the only thing creating gaps in response. If a report was filed under the wrong issue category, municipal staff might not respond. The team learned, for example, that if a community member were to report dumping around an overflowing dumpster, located at a closed business, the report should be made under "maintenance residential" rather than "illegal dumping." Even though the business is closed, the dumpster is associated with a building, and it is the building owner's responsibility. What was submitted as illegal dumping and sent to the Streets department, should have been submitted as a maintenance issue that went to L\&I. The categories that community members and the reporting team thought in differed from the operational framework that municipal department's worked in. For community members using the platform, the most important category was the "what," the violation reported. These 
"maintenance" objects stood in for broader hazards. For municipal departments, the most important information was the "where" or property, which pointed to jurisdiction and responsibility. These insights-illegible addresses, the importance of categories, and distinction between municipal department responsibilities-demonstrated the extent to which public administration operated around property and ownership, which can productively be understood as a part of late industrialism that insists on boundaries even as they are exceeded or no longer make sense.

Philly311 also designed out certain affordances that one would expect of a civic engagement platform that had been recommended by the City to address environmental hazards: There was no way to report air pollution. Observations of environmental hazards that could not be reported through the platform, due to the absence of such a category or the need for ridged adherence to administrative categories, were reported by calling Philly311. The reporting team tracked these separately. These hazards were observed at every reporting trip made by project organizers, but nowhere in the system-neither in Philly311's platform nor by calling AMS—did such complaints seem to register with the City. Open fires, another atmospheric hazard, also fell into this category of unreportable hazard. Although the reporting team never observed open fires, community members continued to report them to both the Fire Department and AMS via phone. In some ways, it made sense that smoke and fire would not be a category in Philly311; in US culture, it is well-established that such incidents should be called into the Fire Department or 911 as an emergency. Yet in Overton, the public was told to use Philly311 to report the burns because they were connected with the scrapyards; when community members attempted this, the platform had no protocol to address open burns as an issue of maintenance, which is what the system had been built for.

The disjuncture between what community members identified as hazards, what they were able to report through municipal channels, and how city departments actually responded stemmed from bureaucratic frames that were anchored by industrial order; which is to say, single object or pollutant regulatory apparatus, and maintenance regimes designed to keep businesses in business. For example, at the time of the reporting project, departments would not re-route miscategorized violations, but simply close them. This suggests a culture where public concern with environmental hazards is rejected rather than investigated if the paperwork isn't filled out correctly. This administrative culture also suggests that to gain breathable air and walkable land would require more than a civic platform that residents could use to signal when trash needed to be picked up. To prevent air pollution in Overton would require a reconfiguration of both the frame of the problem and municipal organization. The City's civic engagement platform was designed to avoid such issues.

The overarching finding of the project was that Philly311 could not do the work that it promised it could do because it was overly functionalist and reinforced the workings of a governing system that could not address the scrapyard problem to begin with. It required appropriation of Philly311, for the purposes of the reporting project, to understand the limitations of the design (such as administrative categories and jurisdictional boundaries) and also to discover blind spots, such as illegible addresses and the absence of some municipal 
departments. This work is civic infrastructuring in the sense that citizens took up the digital platform that promised greater participation in government and used the platform to better understand the workings of public administration, including insight into why the problem exceeded the City's regulatory capacity. Critically, Philly311's infrastructure and data gave community members something tangible to talk through with municipal staff: service request numbers, addresses, administrative categories, and also uploaded pictures, which gained greater credibility when situated within a Philly311 report.

Infrastructuring with Philly311 also enabled the community to better understand the organization of City government, especially the differences between municipal departments and their relationship to each other. The design of Philly311 actually obscures the intricacies of government because it represents public administration monolithically. It was only by tracking reports, and following up with City staff, that the community was able to learn the differences between departments and their relationship to each other. L\&I, for example, could hand out citations and fines to businesses, whereas the Streets department could not. And L\&I did begin to inspect the scrapyards routinely for fenceline violations after the reporting project. A small victory, to be sure, but one that showed that the department took seriously citizens pictures and reports of how businesses were operating in the neighborhood. This in turn convinced community members of the importance of finding the appropriate channels and municipals departments for specific problems. Infrastructuring for a neighborhood they wanted meant leveraging specific tools and relationships strategically, if atomistically.

\section{Conclusion}

While breathing the scrapyards may have been the starting point for political engagement, it was clear that air quality and respiratory health were not issues that the City of Philadelphia had the capacity to address---based on the lack of staff and resources at AMS, and the division's omission from Philly311's system. This is not particularly surprising: Breathing toxic matter in late industrial contexts is largely permissible under current regulatory regimes, where business interests reign over hollowed out environmental agencies (Ottinger 2013; Shapiro 2015, 2019; Murphy 2017a; Ahmann 2018; Fortun 2012). Toxic harm, too, continues to be illegible because of inadequate investment in institutions that could build frameworks to make sense of late industrial health impacts (Liboiron et al. 2018; Spackman 2020). Amid inertia, uncertainty, and neglect, impacted citizens, such as Overton's residents, leveraged existing governing mechanisms, even if imperfectly and outside their range of use, to address environmental health problems.

In and of itself, Philly311 is not a civic technology that can address environmental health problems like Overton's scrapyards. It was not designed to make toxic harm legible, nor enforceable. Philly311 operates according to the same late industrial logics that created the scrapyard mess in the first place, and it extends bureaucratic practices that keep businesses in business by plugging citizens into municipal maintenance systems more efficiently. Unlike other mechanisms of public participation in governance, however-calling reports of hazards into 
municipal departments; the City's planning process; petitioning elected officials--Philly311 did provide the conditions for infrastructuring, which allowed, at the very least, a better understanding of how Philadelphia's administration failed to address the scrapyard problem.

Civic infrastructuring is a public response to late industrial infrastructures that assume that boundaries are never transgressed, that issues can be viewed atomistically, all while disavowing what remains residual. As a response, infrastructuring enables understanding of the nested systems and tight couplings that reinforce government as usual--from legal apparatus to administrative ordering and the information infrastructures that promise to make things more efficient and transparent. The scrapyard reporting project enabled understanding of the problem of governance using civic infrastructure, Philly311, and by framing conversations with municipal staff around the platform's data and categories. Infrastructuring using Philly311 had the effect of extending and building community members' capacity to engage the City on the scrapyards, if piece by piece, violation by violation, under late industrial terms.

\section{Author Biography}

Alison Kenner is Associate Professor of Politics and a faculty member in the Center for Science, Technology, and Society at Drexel University.

\section{Acknowledgements}

I would like to thank the anonymous reviewers, Daniel Lee Kleinman, and Katie Vann for their generative insights, in addition to those by Lindsay Poirier, Chris Kelty, Mike Fortun, and the faculty of the Department of Politics at Drexel University, who workshopped an earlier version of this paper. I would also like to thank students from the Philadelphia Health and Environment Ethnography Lab for supporting this work, particularly Matthew Lesser and Briana Leone, the community organizers who worked on the reporting project, and residents and City staff members who engaged with this research.

\section{References}

Ahmann, Chloe. 2018. "It's exhausting to create an event out of nothing": Slow Violence and the Manipulation of Time." Cultural Anthropology, 33(1):142-171.

Bolívar, Manuel P. R., Pérez, C. C., and Hernández, A. M. L. 2007. "E-Government and Public Financial Reporting The Case of Spanish Regional Governments." The American review of public administration, 37(2):142-177.

Bryer, Thomas A., and Kimberly L. Nelson. 2013. "Social media for civic engagement: An exploration of urban governments." In Citizen E-participation in urban governance: Crowdsourcing and collaborative creativity, 226-246. IGI Global.

Calvillo, Nerea. 2018. "Political airs: From monitoring to attuned sensing air pollution." Social studies of science, $48(3): 372-388$. 
Dillon, Lindsey and Julie Sze. 2016. "Police Power and Particulate Matters: Environmental Justice and the Spatialities of In/Securities in US Cities." English Language Notes 54(2):13-23.

Donaldson, Andrew, S. Lane, N. Ward, and S. Whatmore. 2013. "Overflowing with Issues: Following the Political Trajectories of Flooding." Environment and Planning C: Government and Policy, 31(4):603-618.

Ehn, Pelle. 2008. "Participation in design things." In Proceedings Participatory Design Conference 2008. ACM.

Environmental Protection Agency. 1990. "Brownfield Technical Resources: Industrial \& Analytical Profiles." National Service Center for Environmental Publications. Accessed 22 April 2016. https: / / nepis.epa.gov / Exe / ZyPURL.cgi?Dockey=9100SNAE.txt

Fennell, C., 2011. 'Project Heat'and Sensory Politics in Redeveloping Chicago Public Housing. Ethnography, 12(1): 40-64.

Fortun, Kim. 2012. "Ethnography in late industrialism." Cultural Anthropology, 27(3):446-464.

Fortun, Kim. 2014. "From Latour to Late Industrialism." HAU: Journal of Ethnographic Theory, 4(1):309-329.

Foster, D. 2015. "Taylor to Introduce Legislation to Create Scrap Metal Database." Accessed 4 March 2018, http:/ / www.reptaylor.com/ NewsItemPrint.aspx?NewsID=23639

Hird, Myra J., S.Lougheed, R. Kerry Rowe, and C. Kuyvenhoven. 2014. "Making Waste Management Public (Or Falling Back to Sleep)." Social Studies of Science, 44(3): 441-465.

Irwin, A. \& Michael, M. 2003. Science, social theory \& public knowledge. McGraw-Hill Education (UK).

Jalbert, Kirk and Kinchy, A.J. 2016. "Sense and influence: environmental monitoring tools and the power of citizen science." Journal of Environmental Policy E Planning, 18(3):379-397.

Jasanoff, Sheila. 2003. "Technologies of humility: citizen participation in governing science." Minerva, 41(3):223-244.

Jasanoff, Sheila. 2005. 'Let them eat cake': GM foods and the democratic imagination. In Science and Citizens: Globalization and the Challenge for Engagement, edited by M. Leach, I. Scoones, \& B. Wynne, 183-98. London, UK: Zed Books.

Kimura, Aya H., and Abby Kinchy. Science by the People: Participation, Power, and the Politics of Environmental Knowledge. Rutgers University Press, 2019.

Korn, Matthias, Wolfgang, Reißmann, Röhl, Tobias, and David Sittler, eds. Infrastructuring Publics. Springer, 2018.

Latour, Bruno. 2007. “Turning Around Politics: A Note on Gerard De Vries' Paper." Social Studies of Science, 37(5):811-820.

Latour, B. 2005. Making things public: Atmospheres of democracy. Cambridge, MA: The MIT Press.

Le Dantec, Christopher A. and C. DiSalvo. 2013. "Infrastructuring and the Formation of Publics in Participatory Design." Social Studies of Science, 43(2):241-264.

Le Dantec, Christopher A. "Infrastructures of Digital Civics: Transportation, Advocacy, and Mobile Computing." In Infrastructuring Publics, pp. 169-184. Springer VS, Wiesbaden, 2019. 
Lee, Sang M., X. Tan, and S. Trimi. 2005. "Current Practices of Leading e-Government Countries." Communications of the ACM, 48(10):99-104.

Liboiron, Max, Tironi, M. and Calvillo, N., 2018. "Toxic politics: Acting in a permanently polluted world." Social Studies of Science, 48(3):331-349.

Licht, W. 2000. Getting Work: Philadelphia, 1840-1950. Philadelphia, PA: University of Pennsylvania Press.

Little, Peter C. 2018. "Corporate Mortality Files and Late Industrial Necropolitics." Medical Anthropology Quarterly, 32(2):161-176.

Lubrano, Alfred And J. Gammage. 2019. "Study: Philly among leaders in gentrification, which has pushed out people of color," Philadelphia Inquirer, March 20. Accessed 21 February 2020. https:/ / www.inquirer.com/news / gentrification-philadelphia-african-americanlatino-investment-neighborhood-20190320.html

Mah, Alice. "Ruination and post-industrial urban decline." The SAGE handbook of the 21st century city. London, SAGE Publications Ltd, 201-212.

Marres, Noortje. 2007. "The Issues Deserve More Credit: Pragmatist Contributions to the Study of Public Involvement in Controversy." Social Studies of Science, 37(5):759-780.

Murphy, Michelle. 2017a. "Alterlife and Decolonial Chemical Relations." Cultural Anthropology, 32(4):494-503.

Murphy, M. 2017b. The economization of life. Durham, NC: Duke University Press.

Nading, Alex. 2019. "Ethnography in a grievance." Medicine Anthropology Theory, May 14. http:// www.medanthrotheory.org/read/11310/ethnography-in-a-grievance

Naidu, Prash. 2018. "Sensing Change, Changing Place: Sensory Politics Along the Tasi

Mane." The Asia Pacific Journal of Anthropology, 19(5):467-483.

Norris, Donald and C. Reddick. 2013. "Local E-Government in the United States: Transformation or Incremental Change?" Public Administration Review, 73(1):165-175.

Ottinger, Gwen. 2010. "Buckets of resistance: Standards and the effectiveness of citizen science." Science, Technology, \& Human Values, 35(2):244-270.

Parry, T. 2015. "Metal Scrappers Could Help Us Fight Toxic Mines...If They Can Make It Through the Winter." Grid Magazine, 3 March. Accessed 8 July 2016 http:/ / www.gridphilly.com/grid-magazine/2016/2/25/scrappers

Pine, Jason. 2016. "Last Chance Incorporated." Cultural Anthropology, 31(2):297-318.

Pipek, Volkmar and Wulf, V., 2009. "Infrastructuring: Toward an integrated perspective on the design and use of information technology." Journal of the Association for Information Systems, 10(5):1.

Roberts, Elizabeth F.S., 2017. What Gets Inside: Violent Entanglements and Toxic Boundaries in Mexico City. Cultural Anthropology, 32(4): 592-619.

Shapiro, Nicholas. 2019. Persistent ephemeral pollutants. Being Material.

Shapiro, Nicholas. 2015. "Attuning to the chemosphere: Domestic formaldehyde, bodily reasoning, and the chemical sublime." Cultural Anthropology, 30(3):368-393. 
Spackman, Christy, and Gary A. Burlingame. 2018. "Sensory politics: the tug-of-war between potability and palatability in municipal water production." Social studies of science, 48(3):350-371.

Spackman, Christy. "In smell's shadow: Materials and politics at the edge of perception." Social Studies of Science (2020): 0306312720918946.

Star, Susan Leigh. 1999. "The Ethnography of Infrastructure." American behavioral scientist, 43(3): 377-391.

Star, Susan L., \& Bowker, G. C. 2007. “Enacting silence: Residual categories as a challenge for ethics, information systems, and communication." Ethics and Information Technology, 9(4):273-280.

Star, Susan L. and K. Ruhleder. 1996. "Steps Toward an Ecology of Infrastructure: Design and Access for Large Information Spaces." Information Systems Research, 7(1):111-134.

Thomas, John and G. Streib. 2003. "The new face of government: citizen-initiated contacts in the era of E-Government." Journal of Public Administration Research and Theory: JPART, 13(1):83-102.

Tremblay, Jean-Thomas. 2019. "Feminist Breathing." Differences, 30(3):92-117.

Wylie, Sara, Shapiro, N. and Liboiron, M., 2017. "Making and doing politics through grassroots scientific research on the energy and petrochemical industries." Engaging Science, Technology, and Society, 3:393-425.

Zimring, Carl A. 2009. Cash for your trash: Scrap recycling in America. New Brunswick, NJ: Rutgers University Press. 